\title{
Optimization of the PID-PD parameters of the overhead crane control system by using PSO algorithm
}

\author{
Nur Iffah Mohamed Azmi, Nafrizuan Mat Yahya*, Ho Jun Fu and Wan Azhar Wan Yusoff \\ Faculty of Manufacturing Engineering, Universiti Malaysia Pahang, 26600 Pekan, Pahang, Malaysia
}

\begin{abstract}
The development of combination of proportional-integral-derivative and proportionalderivative (PID-PD) controller for overhead crane is presented. Due to the pendulum-like settings, the swinging of load has caused many difficulties while operating the overhead crane. Swinging of the load causes unnecessary tension to the cable and structure of the overhead crane, which will compromise the safety of operator and other workers. Overhead cranes should have the ability to move the load to desired point as fast as possible while minimizing the load swing and maintaining the accuracy. Proportional-integral-derivative (PID) controller is used for overhead crane positioning and proportional-derivative (PD) controller for load oscillation. New time-domain performance criterion function is used in particle swarm optimization (PSO) algorithm for the tuning of the PID-PD controller rather than the general performance criteria using error of the system. This performance criterion function monitors the performance in terms of rise time, overshoot, settling time and steady state error of the overhead crane system. The performance of the optimised PID-PD controller is verified with simulation in MATLAB. The PSO optimized PID-PD controllers with new performance criterion are shown effective in improving the step response of the overhead crane position as well as controlled the load oscillation.
\end{abstract}

Keywords: particle swarm optimization, PID controller, PD controller, overhead crane control system.

\section{Introduction}

Overhead cranes are commonly used in industrial fields such as harbour and factories. An overhead crane can be used for loading or unloading raw materials in warehouse, lifting heavy parts or components in production lines, or feeding materials in manufacturing plant.

An overhead crane is normally operated by trained operator [1]. During operations, the load of an overhead crane is free to swing like a pendulum. To increase productivity, modern cranes are operated at higher speed which can lead to dangerous situations and failure of the crane mechanism [2]. The precise positioning by an operator using only visual feedback is difficult due to the pendulum-like swinging motion exhibited by the load [3].

Problems of overhead cranes have driven many researchers to develop control algorithms to automate the operations of overhead cranes. Investigations show that the performance of the implementing controller in crane system is satisfactory in minimizing the swinging of the load [4].

In order to achieve fast and accurate load positioning, researchers have proposed several controls for overhead crane system. Fang et al. proposed simple PD controller to asymptotically control the overhead crane dynamics and two nonlinear controller that increase the coupling between the load and the gantry position [3]. The increased in coupling between the gantry and payload shows an improved in transient response [3]. In 2016, Albert and Aswin also proposed control systems of PID controller and fuzzy logic controller to eliminate the swing problem of overhead cranes [5]. There are also researches and studies on hybrid controllers for optimization of overhead crane. Hai et al. proposed an anti-sway tracking control, PID-Fuzzy Sliding Mode control (PID-FSMC) algorithm for two dimensional crane system [6].

There are many control algorithms have been developed to optimized the controller in term of swing, travel time and precision control of overhead cranes. Smoczek and Szpytko proposed a controller based on Particle Swarm Optimization (PSO) to solve the problem of the load swing [7]. Another PSO based PID controller also introduced to obtain the optimal parameters according to the priority of time response [8]. GA-based PID+PD controller was proposed by Solihin et al. for automatic gantry crane system where PID controller for

* Corresponding author: nafrizuanmy@ump.edu.my 
positioning control and PD controller for swing damping [9]. In 2010, Petrenko and Alavi proposed an improved fuzzy logic controller that based on genetic algorithm to estimate parameters and generate the fuzzy rules [10].

In the following topics, a brief discussion about PID controller and performance criteria are presented. Next, PSO algorithm is showed in detail. Further, the methodology of developing overhead crane system and implementation of PSO-PID controller are discussed. Finally, the results and its discussion based on the accuracy and travel time in term of maximum overshoot, steady state error, rise time and settling time of the system are well described and followed by the conclusion of this paper.

\section{PID controller and its performance criteria}

Even though many new control techniques based on optimisation procedures have been proposed, PID controller is still using in industrial applications [11]. PID controller has a simple structure which is easy to be understood and tuned by anyone with some basic knowledge in control engineering $[12,13]$. But the tuning of the controller parameters, which are proportional gain $K_{P}$, integral gain $K_{I}$, and derivative gain $K_{D}$ need to be done appropriately for satisfactory control performances [11]. One of the main research about PID controller is the tuning rules. Many methods have been emerged to determine the PID controller parameters in the past decades [11].

PID controller is used to improve the dynamic response as well as to reduce or eliminate the steady-state error. The derivative controller adds a finite zero to the open-loop plant transfer function and improves the transient response. The integral controller adds a pole at the origin, thus increasing system type by one and reducing the steady state-error due to a step function to zero [14].

PID controller in continuous form with input $e(\cdot)$ and output $u_{p i d}(\cdot)$, is given generally as [15]:

$$
u_{p i d}(t)=K_{P}\left[e(t)+\frac{1}{T_{i}} \int_{0}^{t} e(\tau) d \tau+T_{d} \frac{d}{d t} e(t)\right]
$$

or

$$
u_{\text {pid }}(t)=K_{P} e(t)+K_{I} \int_{0}^{t} e(\tau) d \tau+K_{D} \frac{d}{d t} e(t)
$$

Where $K_{P}$ is the proportional gain, $T_{i}$ is the integral time constant, $T_{d}$ is the derivative time constant; $K_{I}=\frac{K_{P}}{T_{i}}$ is the integral gain and $K_{D}=K_{P} T_{d}$ is the derivative gain respectively.

The transfer function of PID controller will be in the form of:

$$
C(s)=K_{P}+\frac{K_{I}}{s}+K_{D} s
$$

The design of controller is to minimise the system error by anticipating the inputs, where the error of the system is the difference between desired response and actual input. The measure of the system error is used as the performance criteria. In general, the performance criteria of PID controller design is listed as in Table 1 below.

Table 1. Performance criteria of PID controller [16].

\begin{tabular}{|c|c|}
\hline Name of criterion & Formula \\
\hline $\begin{array}{c}\text { Integral of the Absolute Error } \\
\text { (IAE) }\end{array}$ & $I A E=\int_{0}^{\infty}|e(t)| d t$ \\
\hline $\begin{array}{c}\text { Integral of Square Error } \\
\text { (ISE) }\end{array}$ & $I A E=\int_{0}^{\infty} e(t)^{2} d t$ \\
\hline $\begin{array}{c}\text { Integral of Time-weighted } \\
\text { Square Error (ITSE) }\end{array}$ & $I A E=\int_{0}^{\infty} t e(t)^{2} d t$ \\
\hline $\begin{array}{c}\text { Integral of Time-weighted } \\
\text { Absolute Error (ITAE) }\end{array}$ & $I A E=\int_{0}^{\infty} t|e(t)| d t$ \\
\hline
\end{tabular}

A disadvantage of IAE and ISE criteria in minimisation is they weights all errors equally independent of time which results in response with relatively small overshoot but long settling time. Even with ITSE criteria weighting errors with time, the analytical formula with derivative processes are complex and time consuming. ITAE is simpler and consume lesser time than ITSE with results in conservative settings. Without discriminating large initial error in the response following step demand, the ITAE is a popular performance criteria. But ITAE penalize smaller errors at a later time $[16,17]$.

Therefore, a new performance criterion by Gaing in the time domain is to evaluate the PID-PD controller parameters is used in this paper [14]. A set of good control parameters $K_{P}, K_{I}$, and $K_{D}$ in performance criteria minimisation can yield a good step response in the time domain. These performance criteria in the time domain include maximum overshoot $\left(M_{P}\right)$, rise time $\left(T_{R}\right)$, settling time $\left(T_{S}\right)$ and steady-state error $\left(E_{S S}\right)$. The new performance criterion is defined as follows [14]:

$$
W(K)=\left(1-e^{-\beta}\right) \cdot\left(M_{P}+E_{S S}\right)+e^{-\beta} \cdot\left(T_{S}-T_{R}\right)
$$

where

$\beta \quad$ weighing factor

$K \quad$ array consisting $K_{P}, K_{I}$ and $K_{D}$ :

$$
K=\left[K_{P}, K_{I}, K_{D}\right]
$$

Weighing factor, $\beta$ can be set to be larger than 0.7 to reduce the overshoot and steady-state error or smaller than 0.7 to reduce the rise time and settling time. By setting the value, $\beta$ can be used to satisfy the requirements of designer. In this paper, $\beta$ is set to 0.7 .

To evaluate the performance criteria of each individual in the population, evaluation function given in equation (6) is used for each individual in every 
population in the algorithm. The evaluation function is a reciprocal of the performance criterion as in equation (4). The value of the function indicates that the smaller the value of individual, the higher the evaluation value.

$$
f=\frac{1}{W(K)}
$$

\section{PSO algorithm}

Particle swarm optimization (PSO) is an optimization method by Shi and Eberhart [19]. It is developed based on flock movement behaviour of bird and fish [20]. PSO was proposed for computational intelligence by exploiting simple social interaction rather than mere cognitive abilities [18]. Bai stated that PSO is an optimization algorithm, a heuristic global optimization method [20]. PSO is widely used for its easy implementation and the requirement of few particles to be tuned [20]. Shi and Eberhart also stated that the few parameters adjustment of PSO makes it widely used for optimizations [21]. Since the introduction of particle swarm algorithm in 1995, it was evaluated with promising future application areas such as human tremor analysis, product mix optimization, and power system load stabilization [21].

PSO is derived from the social-psychological theory, and has been found to be perform well in complex systems. PSO is an excellent optimization methodology and shows promising performance for obtaining optimal PID controller parameters [14]. With new parameter called inertia weight, $w$ is added by Shi and Eberhart, this modified version has become the commonly used PSO where the inertia weight decreases linearly along with the iterations [19].

Each particle in PSO represents a potential solution to a problem in $g$-dimensional search space. The coordinate which linked to the best evaluation value of the particles has achieved so far is keep tracked and this value is called pbest. Another value that is being tracked is called gbest. gbest is the overall best value and location of any particle, obtained in the group [14, 17].

Each particle in PSO adjusts its "flying" in the $g$ dimensional search space according to its own and companion's "flying" experience with its own velocity. At each time step (iteration), the particles change their velocities and "fly" toward the pbest and gbest values. The particles updates their location at every time step as they "fly" in the search space $[19,22]$.

The changing of the velocity of each particle toward its pbest and gbest locations at each iteration according to the following equation:

$$
\begin{aligned}
v_{j, g}^{t+1}= & w \cdot v_{j, g}^{t}+c_{1} * \operatorname{rand}() *\left(\text { pbest }_{j, g}-x_{j, g}^{t}\right) \\
& +c_{2} * \operatorname{rand}() *\left(\text { gbest }-x_{j, g}^{t}\right)
\end{aligned}
$$

where

$$
\begin{gathered}
v_{g}^{\min }<v_{j, g}^{t}<v_{g}^{\max } \\
w=w_{\max }-\frac{w_{\max }-w_{\min }}{i t e r_{\max }} \times \text { iter }
\end{gathered}
$$

With the velocity updated, the position of each particle will be modified according to the following equation:

$$
\begin{gathered}
x_{j, g}^{t+1}=x_{j, g}^{t}+v_{j, g}^{t+1} \\
j=1,2, \cdots, n ; \\
g=1,2, \cdots, m ;
\end{gathered}
$$

where

$m \quad$ number of members in a particle;

$n \quad$ number of particles in a group;

$t$ iterations;

$v_{j, g}^{t+1} \quad$ velocity of particle $j$ at iteration $t+1$;

$w \quad$ inertia weight factor;

$c_{1}, c_{2} \quad$ acceleration factor;

rand( ) random number between 0 and 1;

$x_{j, g}^{t} \quad$ current position of particle $j$ at iteration $t$;

pbest $_{j, g} \quad$ pbest of particle $j$, member $g$;

gbest $_{g}$ gbest of the group.

\section{Methodology}

\subsection{Model of overhead crane}

The model of the overhead crane is first developed with schematic diagram and later the equation of the model is formulated. Schematic diagram of overhead crane model is shown in Figure 1 below. In the Figure 1, $m_{1}, m_{2}, l, x, \theta, T_{L}$ and $F$ are payload mass, trolley mass, cable length, horizontal position of trolley, swing angle, torque and driving force. Nonlinear model of the gantry crane system is modelled based on [23]. The equation of motion of the overhead crane model is:

$$
\begin{gathered}
F=\left(m_{1}+m_{2}\right) \ddot{x}+m_{1} l \ddot{\theta} \cos \theta-m_{1} l \dot{\theta}^{2} \sin \theta+D \dot{x} \\
0=l \ddot{\theta}+\ddot{x} \cos \theta+g \sin \theta
\end{gathered}
$$

With the overhead crane driven by DC motor, the dynamic of the DC motor is considered and the complete nonlinear differential equation of the overhead crane is obtained as follow:

$$
V=A \ddot{x}+B \dot{x}+C[\ddot{\theta} \cos \theta-\dot{\theta} \sin \theta]
$$

For small $\theta, \sin \theta \approx \theta$ and $\cos \theta \approx 1$; the linearized model equation is:

$$
V=A \ddot{x}+B \dot{x}+C \ddot{\theta}
$$


where

$$
\begin{aligned}
& A=\frac{R r_{p}}{K_{t} z}\left(m_{1}+m_{2}\right) \quad B=\frac{R D r_{p}}{K_{t} z}+\frac{K_{e} z}{r_{p}} \\
& C=\frac{R r_{p}}{K_{t} z}\left(m_{1} l\right)
\end{aligned}
$$

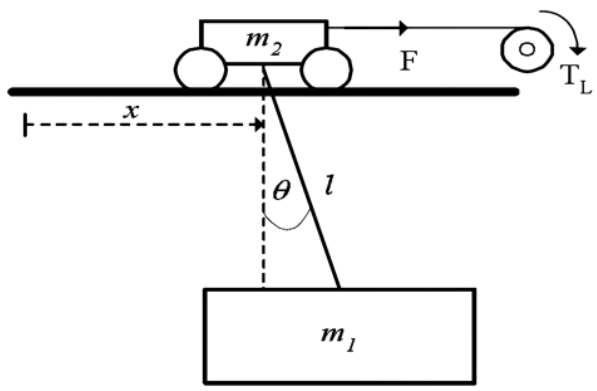

Fig. 1. Schematic diagram of overhead crane model with DC motor [23].

Table 2. List of parameters.

\begin{tabular}{|c|c|c|}
\hline Parameter & Value & Unit \\
\hline Load mass, $m_{1}$ & 1.0 (nominal) & $\mathrm{kg}$ \\
\hline Overhead crane mass, $m_{2}$ & 5.0 & $\mathrm{~kg}$ \\
\hline Cable length, $l$ & 2.0 (nominal) & $\mathrm{m}$ \\
\hline Gravitational force, $g$ & 9.81 & $\mathrm{~m} / \mathrm{s}^{2}$ \\
\hline Damping, $D$ & 12.32 & $\mathrm{Ns} / \mathrm{m}$ \\
\hline Resistance, $R$ & 2.6 & $\mathrm{Ohm}$ \\
\hline Torque constant, $K_{t}$ & 0.007 & $\mathrm{Nm} / \mathrm{A}$ \\
\hline Electric constant, $K_{e}$ & 0.007 & $\mathrm{Vs} / \mathrm{rad}$ \\
\hline Radius of pulley, $r_{p}$ & 0.02 & $\mathrm{~m}$ \\
\hline Gear ratio, $z$ & 15 & - \\
\hline
\end{tabular}

The structure of the overhead crane with PID and PD controller is shown in Figure 2 below.

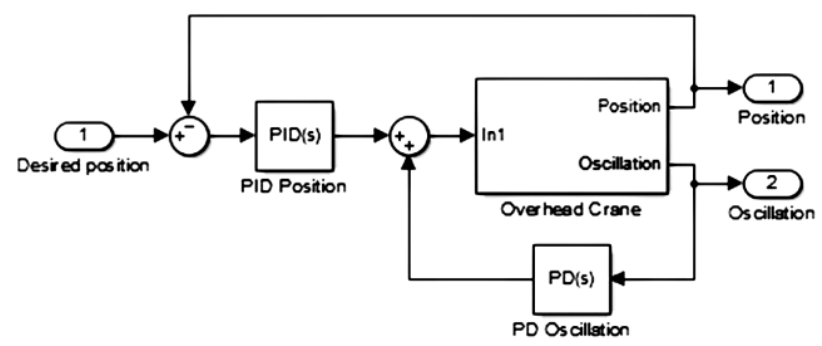

Fig. 2. Control structure of overhead crane with PID and PD controller.

\subsection{PSO-PID-PD tuning}

To control the position of the overhead crane, PID controller is implemented while for load oscillation control, PD controller is used. To tune the parameters, PSO algorithm is used. "Individual" is used to represent the "particle". The PID and PD controller parameters $K_{P}, K_{I}, K_{D}, K_{P S}$ and $K_{D S}$ composed an individual.
There are five members in an individual and are assigned a random values. The dimension of a population is $n \times 5$, where $n$ is the number of individuals in a population. Good step responses can be achieved with a set of good control parameters $K_{P}, K_{I}, K_{D}, K_{P S}$ and $K_{D S}$ which will result in the minimisation of performance criteria in the time domain including the settling time, rise time, maximum overshoot and steady state error of the overhead crane position and load oscillation.

To evaluate the performance criteria of each individual in the population, evaluation function given in equation (14) is used in every population in the algorithm. The evaluation function consists of the performance criteria from PID and PD controllers of the overhead crane system for position and load oscillation.

$$
f=\frac{f_{p}}{f_{p}+f_{s}}\left(f_{p}\right)+\frac{f_{s}}{f_{p}+f_{s}}\left(f_{s}\right)
$$

where

$$
f_{p}=\frac{1}{W_{P}(K)} \quad f_{s}=\frac{1}{W_{S}(K)}
$$

The performance criteria for the evaluation function are defined as below:

$$
\begin{aligned}
W_{P}(K)= & \left(1-e^{-\beta}\right) \cdot\left(M_{P}^{p o s}+E_{S S}^{p o s}\right)+e^{-\beta} \\
& \cdot\left(T_{S}^{\text {pos }}-T_{R}^{p o s}\right) \\
W_{S}(K)= & \left(1-e^{-\beta}\right) \cdot\left(M_{P}^{O C S}+E_{S S}^{O C S}\right)+e^{-\beta} \\
& \cdot\left(T_{S}^{O C S}-T_{R}^{O C S}\right)
\end{aligned}
$$

where

$K \quad\left[K_{P}, K_{I}, K_{D}, K_{P S}, K_{D S}\right]$;

$M_{P}^{p o s} \quad$ Overshoot of step response of overhead crane position;

$E_{S S}^{p o s} \quad$ Steady state error of step response of overhead crane position;

$T_{s}^{p o s} \quad$ Settling time of step response of overhead crane position;

$T_{R}^{p o s} \quad$ Rise time of step response of overhead crane position;

$M_{P}^{O S C} \quad$ Overshoot of step response of overhead crane load oscillation;

$E_{S S}^{O C S} \quad$ Steady state error of step response of overhead crane load oscillation;

$T_{S}^{\text {oCS }} \quad$ Settling time of step response of overhead crane load oscillation;

$T_{R}^{\text {OCS }} \quad$ Rise time of step response of overhead crane load oscillation.

Before evaluating the evaluation value of an individual, the Routh-Hurwitz criterion is utilized to test the stability of the closed-loop system. The individual satisfies the Routh-Hurwitz stability test applied to the characteristic equation of the system means that it is a 
practical individual and the value of $W_{P}(K)$ and $W_{S}(K)$ are small.

The steps of the search of PSO-PID-PD is as follow $[14,17]$ :

Step 1: Specify the number populations and iterations. Generate random number for members in particles $K$ with dimension of $n \times 5$, where $n$ is the number of population and $K=\left[K_{P}, K_{I}, K_{D}, K_{P S}, K_{D S}\right]$.

Step 2: Use Routh-Hurwitz criterion to test the closedloop system stability for each particle $K$.

Step 3: Calculate the value of the performance criteria in terms of $M_{P}^{\text {pos }}, E_{S S}^{\text {pos }}, T_{S}^{\text {pos }}, T_{R}^{\text {pos }}, M_{P}^{O S C}$, $E_{S S}^{O C S}, T_{S}^{O C S}$ and $T_{R}^{O C S}$ according to equation (15) and equation (16).

Step 4: Evaluate the performance criteria of each particle in the population using evaluation value, $f$ as shown in equation (14).

Step 5: Compare the evaluation value of each particle and set as pbest. The maximum value among pbest is then denoted as gbest.

Step 6: Calculate new velocity, $v$ of each particle $K$ using equation (17) below:

$$
\begin{aligned}
v_{j, g}^{t+1}= & w \cdot v_{j, g}^{t}+c_{1} * \operatorname{rand}() *\left(\text { pbest }_{j, g}-K_{j, g}^{t}\right) \\
& +c_{2} * \operatorname{rand}() *\left(\text { gbest }_{g}-K_{j, g}^{t}\right)
\end{aligned}
$$

where

$$
j=1,2, \cdots, n \quad g=1,2,3
$$

$n \quad$ number of population;

$t \quad$ iteration;

$v_{j, g}^{t+1} \quad$ velocity of particle $j$ at iteration $t+1$

$w \quad$ inertia weight factor;

$c_{1}, c_{2} \quad$ acceleration factor;

rand( ) random number between 0 and 1;

$x_{j, g}^{t} \quad$ current position of particle $j$ at iteration $t$;

pbest $_{j \cdot g} \quad$ pbest of particle $j$, member $g$;

gbest $_{g}$ gbest of the iteration;

$v_{j, 1}=$ Change in velocity of $K_{P}$;

$v_{j, 2}=$ Change in velocity of $K_{I}$;

$v_{j, 3}=$ Change in velocity of $K_{D}$;

below:

and the value of $w$ is set according to equation

$$
w=w_{\max }-\frac{w_{\max }-w_{\min }}{\text { iter }_{\max }} \times \text { iter }
$$

Step 7: Check the boundary condition of the velocity, $v$ according to Table 3 .

$$
\begin{aligned}
& \text { If } v_{j, g}^{t+1}>V_{g}^{\max } \text {, then } v_{j, g}^{t+1}=V_{g}^{\max } \\
& \text { If } v_{j, g}^{t+1}<V_{g}^{\min } \text {, then } v_{j, g}^{t+1}=V_{g}^{\min }
\end{aligned}
$$

where

$$
j=1,2, \cdots, n \quad g=1,2,3
$$

Table 3. Particles velocity boundaries.

\begin{tabular}{|c|c|}
\hline Parameters & Value \\
\hline$v_{K_{P}}^{\min }$ & -2.5 \\
\hline$v_{K_{P}}^{\max }$ & 2.5 \\
\hline$v_{K_{t}}^{\min }$ & -1.0 \\
\hline$v_{K_{I}}^{\max }$ & 1.0 \\
\hline$v_{K_{D}}^{\min }$ & -1.5 \\
\hline$v_{K_{D}}^{\max }$ & 1.5 \\
\hline$v_{K_{P s}}^{\min }$ & -2.5 \\
\hline$v_{K_{P s}}^{\max }$ & 2.5 \\
\hline$v_{K_{D S}}^{\min }$ & 1.5 \\
\hline$v_{K_{D S}}^{\max }$ & -1.5 \\
\hline
\end{tabular}

$V_{g}^{\max }$ and $V_{g}^{\min }$ are calculated based on equations (19) and (20) below:

$$
\begin{gathered}
V_{g}^{\max }=\left(K_{g}^{\max }-K_{g}^{\min }\right) \times 0.01 \\
V_{g}^{\min }=-\left(K_{g}^{\max }-K_{g}^{\min }\right) \times 0.01
\end{gathered}
$$

Step 8: Update and modify the position of each member in particle $K$ using equation (21) and check for boundary violation according to values in Table 4.

$$
K_{j, g}^{t+1}=K_{j, g}^{t}+v_{j, g}^{t+1}
$$

where

$$
K_{g}^{\min } \leq K_{j, g}^{t+1} \leq K_{g}^{\max }
$$

Table 4. PSO algorithm PID-PD controller parameters boundaries.

\begin{tabular}{|c|c|}
\hline Parameters & Value \\
\hline$K_{P}^{\min }$ & -50 \\
\hline$K_{P}^{\max }$ & 200 \\
\hline$K_{I}^{\min }$ & -50 \\
\hline$K_{I}^{\max }$ & 50 \\
\hline$K_{D}^{\min }$ & -50 \\
\hline$K_{D}^{\max }$ & 100 \\
\hline$K_{P S}^{\min }$ & -50 \\
\hline$K_{P S}^{\max }$ & 200 \\
\hline$K_{D S}^{\min }$ & -50 \\
\hline$K_{D S}^{\max }$ & 100 \\
\hline
\end{tabular}


The lower boundaries are set to negative values so that PSO algorithm can explore a wider range of values for more optimum PID-PD controller parameters.

Step 9: Repeat Step 3 to Step 9 if the number of maximum iteration is not met. Otherwise, go to Step 10.

Step 10: The individuals of the latest gbest is the optimal PID-PD controller parameter.

\section{Results and discussion}

The simulation of the overhead crane system with PIDPD controllers was done in MATLAB R2014a and Simulink using Intel Core i5-3230M Processor, 2.60GHz, 8GB RAM.

PSO algorithm with new time-domain performance criterion, equation (4) is used to tune and obtain the five optimal parameters of PID and PD controllers, where the function is evaluated using equation (14). In this simulation, 50 particles are used with 100 iterations. By default, $c_{1}$ and $c_{2}$ are set to 2 . The initial value of $w$ is 0.9 and linearly decreased to 0.4 with iterations. Table 5 shows the optimal PID and PD gain parameters obtained using the PSO algorithm with new time-domain performance criterion. The upper and lower boundary of the PID controller gains' parameters of PSO algorithm used in the simulation are shown in Table 3. The lower boundaries are set to negative values so that PSO algorithm can explore a wider range of values for more optimum PID and PD controller parameters.

The simulation of the overhead crane system with PSO tuned PID-PD controller implemented is conducted in MATLAB and the performance of the position and swing angle with nominal values $m_{1}=1.0 \mathrm{~kg}$ and $l=2.0$ $\mathrm{m}$ is obtained and shown in Figure 3 with values shown in Table 6. The PID-PD parameters obtained from PSO algorithm is shown in Table 5. Later, the overhead crane system is conducted with various reference positions and load masses. The performances are shown in Figure 4 and Figure 5, and the values are tabulated in Table 7 and Table 8.

Table 5. PID-PD parameter based on PSO optimisation with new time-domain performance criteria.

\begin{tabular}{|c|c|}
\hline PID Gain & Parameter \\
\hline$K_{P}$ & 84.1346 \\
\hline$K_{I}$ & 0.0766 \\
\hline$K_{D}$ & 3.9477 \\
\hline$K_{P S}$ & 77.1693 \\
\hline$K_{D S}$ & -28.6481 \\
\hline
\end{tabular}

Table 6. Performance of overhead crane with nominal reference position $(1.0 \mathrm{~m})$ and load mass $(1.0 \mathrm{~kg})$ using PSO optimised PID-PD controller.

\begin{tabular}{|c|c|c|c|c|}
\hline \multicolumn{5}{|c|}{ Performance } \\
\hline \multicolumn{3}{|c|}{ Position } & \multicolumn{2}{c|}{ Oscillation } \\
\hline$E_{S S}(\mathbf{m})$ & $M_{P}(\mathbf{\%})$ & $T_{S}(\mathbf{s})$ & $\theta_{\max }(\mathbf{r a d})$ & $T_{S}(\mathbf{s})$ \\
\hline 0.000 & 9.341 & 5.740 & 0.1938 & 7.708 \\
\hline
\end{tabular}
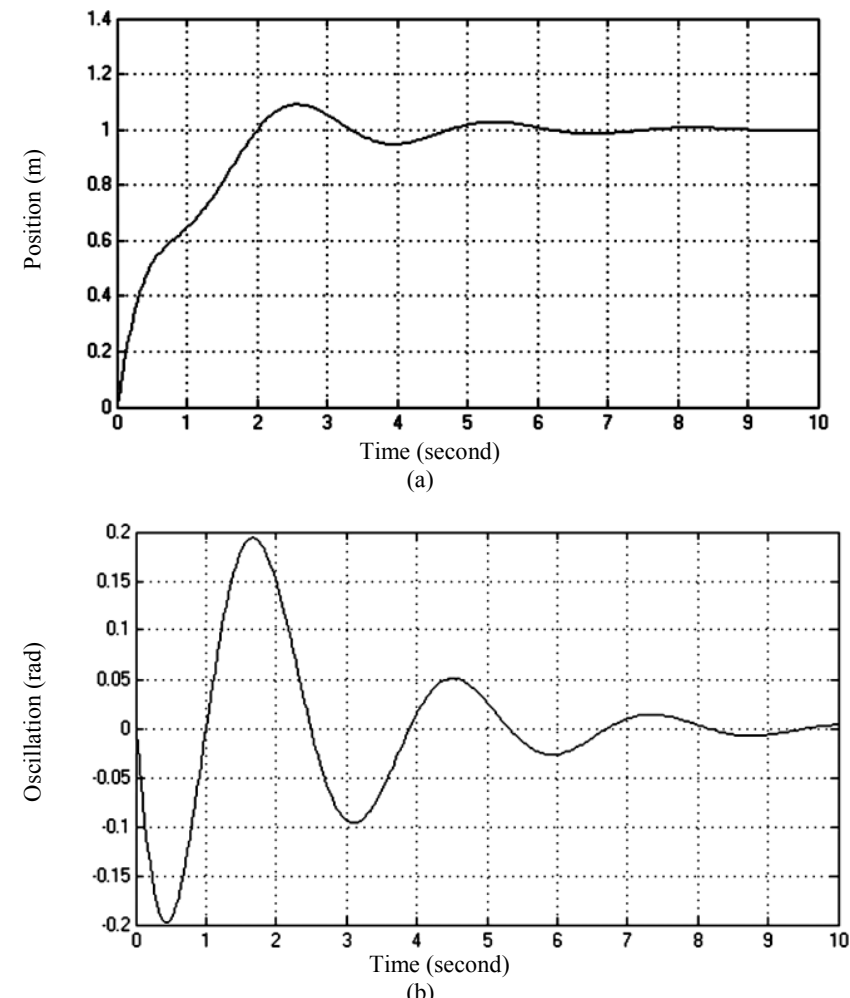

(b)

Fig. 3. System responses with $1.0 \mathrm{~m}$ reference point and $1.0 \mathrm{~kg}$ load.
(a) Overhead crane position.
(b) Load oscillation.

To test the robustness of the PID-PD parameters, performance of the overhead system is tested with various reference position and load mass. The performance with reference position of $1.5 \mathrm{~m}$ and $2.0 \mathrm{~m}$ are tested, while $5.0 \mathrm{~kg}$ and $20.0 \mathrm{~kg}$ of load masses are tested for load oscillation.

From Figure 4 (a), the step responses of various reference positions are similar with same overshoot. The settling time for overhead crane positions are around 5.7 seconds and slightly decreases from 5.740 seconds to 5.726 seconds as the reference position increases from $1.0 \mathrm{~m}$ to $2.0 \mathrm{~m}$. This shows that the overhead crane trolley can achieve higher velocity with greater acceleration as the reference position increases.

As for the load oscillation, the maximum angle increases from 0.1938 radians $\left(11.1039^{\circ}\right)$ to 0.3876 radians $\left(22.2078^{\circ}\right)$. The settling time $(0.01 \mathrm{~s})$ of the load oscillation increases from 7.708 seconds to 9.145 seconds as the reference position increases. The increase in maximum angle can be caused by the greater acceleration of the trolley as it travel. 
Table 7. Performance of overhead crane with various reference point and $1.0 \mathrm{~kg}$ load mass.

\begin{tabular}{|c|c|c|c|c|c|}
\hline \multirow{3}{*}{$\begin{array}{c}\text { Desired } \\
\text { position }(m)\end{array}$} & \multicolumn{5}{|c|}{ Performance } \\
\hline & \multicolumn{3}{|c|}{ Position } & \multicolumn{2}{|c|}{ Oscillation } \\
\hline & $\begin{array}{l}E_{S S} \\
(\mathbf{m})\end{array}$ & $\begin{array}{l}M_{P} \\
(\%)\end{array}$ & $\begin{array}{l}T_{S} \\
\text { (s) }\end{array}$ & $\begin{array}{c}\theta_{\max } \\
\text { (rad) }\end{array}$ & $\begin{array}{l}T_{S} \\
\text { (s) }\end{array}$ \\
\hline 1.0 & 0.000 & 9.341 & 5.740 & 0.1938 & 7.708 \\
\hline 1.5 & 0.000 & 9.341 & 5.737 & 0.2907 & 8.967 \\
\hline 2.0 & 0.000 & 9.341 & 5.726 & 0.3876 & 9.145 \\
\hline
\end{tabular}

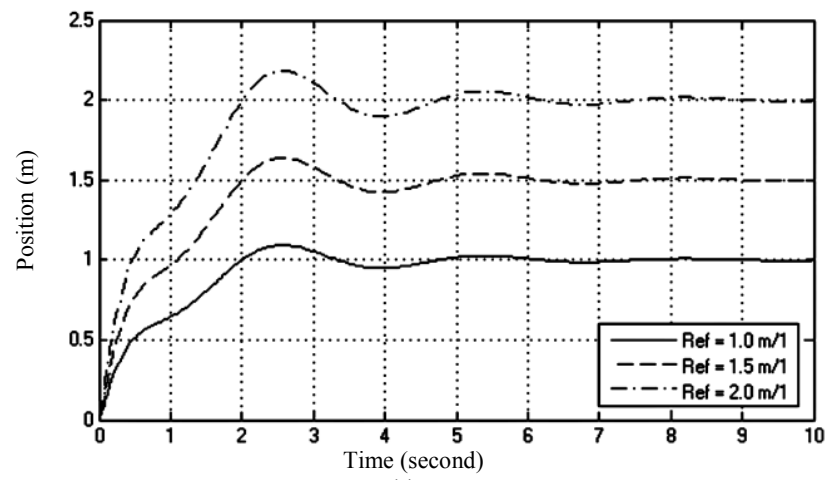

(a)

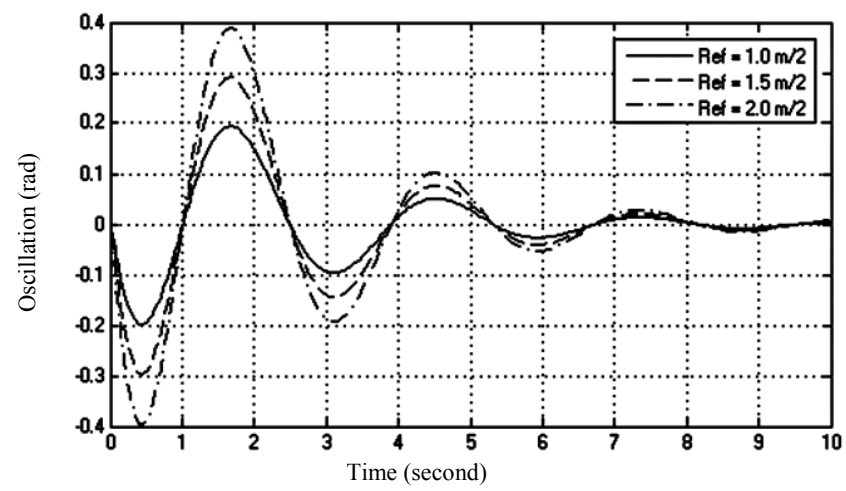

(b)

Fig. 4. System responses with various reference point and 1.0 $\mathrm{kg}$ load mass.

(a) Overhead crane position. (b) Load oscillation.

From Figure 5 (a), the step responses of various loads are similar with different overshoot. The overshoot increases from $9.341 \%$ to $14.368 \%$ as the loads increases from $1.0 \mathrm{~kg}$ to $20.0 \mathrm{~kg}$. The settling time for overhead crane position slightly decreases from 5.740 seconds to 5.628 seconds as the load increases. This shows that it is harder to control the trolley with a greater load.

As for the load oscillation, the maximum angle increases from 0.1938 radians $\left(11.1039^{\circ}\right)$ to 0.2336 radians $\left(3.3843^{\circ}\right)$. The settling time $(0.01 \mathrm{~s})$ of the load oscillation decreases from 7.708 seconds to 7.156 seconds as the load increases. Simulation results with higher load show greater maximum swing angle but the time required to settle down is much lesser.
Table 8. Performance of overhead crane with $1.0 \mathrm{~m}$ reference point and various loads mass.

\begin{tabular}{|c|c|c|c|c|c|}
\hline \multirow{2}{*}{$\begin{array}{c}\text { Load } \\
\mathbf{( k g}\end{array}$} & \multicolumn{4}{|c|}{ Performance } \\
\cline { 2 - 6 } & \multicolumn{3}{|c|}{ Position } & \multicolumn{2}{c|}{ Oscillation } \\
\cline { 2 - 6 } & $E_{S S}$ & $M_{P}$ & $T_{S}$ & $\theta_{\max }$ & $T_{S}$ \\
$(\mathbf{m})$ & $\mathbf{( \% )}$ & $(\mathbf{s})$ & $(\mathbf{r a d})$ & $(\mathbf{s})$ \\
\hline 1.0 & 0.000 & 9.341 & 5.740 & 0.1938 & 7.708 \\
\hline 5.0 & 0.000 & 10.556 & 5.702 & 0.2037 & 7.566 \\
\hline 20.0 & 0.000 & 14.368 & 5.628 & 0.2336 & 7.156 \\
\hline
\end{tabular}

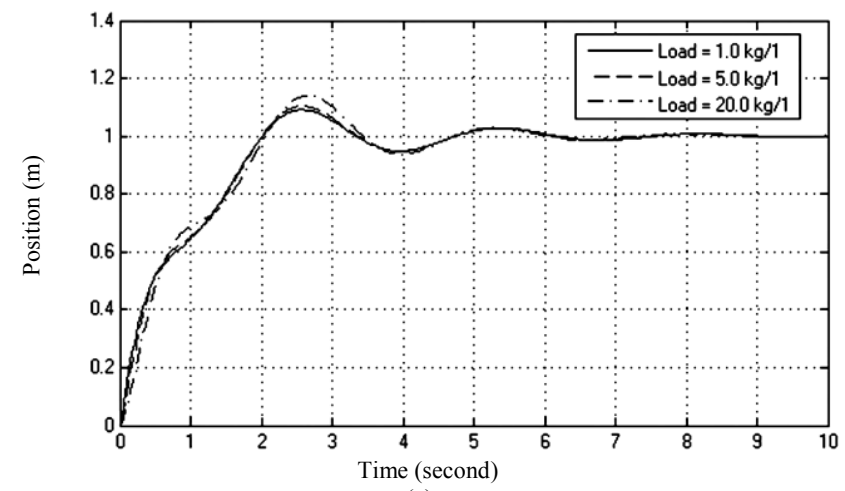

(a)

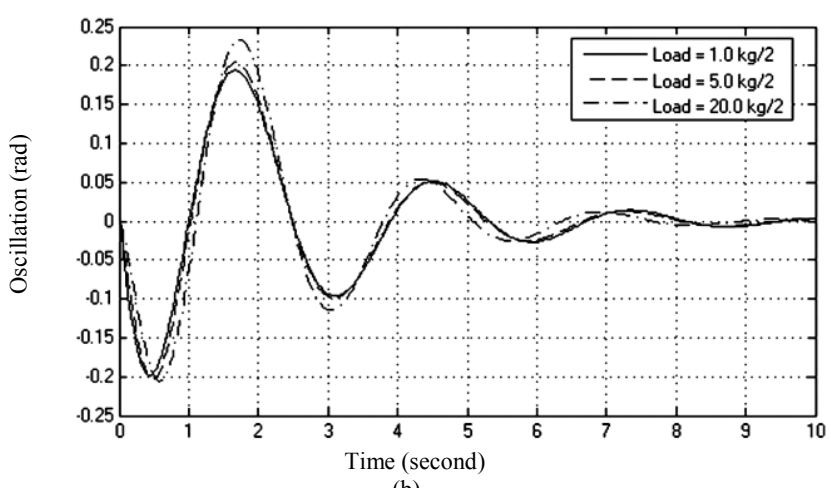

(b)

Fig. 5. System response with $1.0 \mathrm{~m}$ reference point and various loads mass.

(a) Overhead crane position. (b) Load oscillation.

\section{Conclusion}

The optimisation of the overhead crane control system using PSO tuned PID-PD controller is presented. With the new time-domain performance criterion used in evaluating the settling time $\left(T_{S}\right)$, rise time $\left(T_{R}\right)$, maximum overshoot $\left(M_{P}\right)$, and steady state error $\left(E_{S S}\right)$ for position and load oscillation, optimal PID and PD controller parameters are obtained. The parameters obtained from the PSO tuning are evaluated with step responses of the overhead crane system. The PSO tuned PID-PD controller parameters shown are effective in moving the overhead crane as fast as possible without any steady state error with low load oscillation. 


\section{Acknowledgment}

This research is funded by the University Malaysia Pahang under research grant RDU180386. The authors would like to thank University Malaysia Pahang for encouraging this research.

\section{References}

1. H.M. Omar, A. Nayfeh, Control of gantry and tower cranes, Virginia Polytech. Inst. State Univ., PhD Thesis (2003)

2. L.A. Tuan, J.J. Kim, S.G. Lee, T.G. Lim, L.C. Nho, Second-order sliding mode control of a 3D overhead crane with uncertain system parameters, Int. J. Precis. Eng. Manuf., 15, 5, 811-819 (2014)

3. Y. Fang, E. Zergeroglu, W.E. Dixon, D.M. Dawson, Nonlinear coupling control laws for an overhead crane system, IEEE/ASME Trans. Mechatronics, 8, 3, 418-423 (2001)

4. H. Park, D. Chwa, K.-S. Hong, A feedback linearization control of container cranes: Varying rope length, Int. J. Control Autom. Syst., 5, 4, 379387 (2007)

5. A.S. Albert, R.B. Aswin, A fuzzy logic controller for the operation of an overhead crane control problem, Int. Res. J. Eng. Technol., 3, 7, 1420-1424 (2016)

6. L.X. Hai, T.H. Nguyen, T.G. Khanh, N.T. Thanh, B.T. Duong, P.X. Minh, Anti-sway tracking control of overhead crane system based on PID and fuzzy sliding mode control, J. Sci. Technol., 55, 1, 116-127 (2017)

7. J. Smoczek, J. Szpytko, Particle swarm optimizationbased multivariable generalized predictive control for an overhead crane, IEEE/ASME Trans. Mechatronics, 22, 1, 258-268 (2017)

8. D.V. Diep, V.V. Khoa, PID-controllers tuning optimization with pso algorithm for nonlinear gantry crane system, Int. J. Eng. Comput. Sci., 3, 6, 66316635 (2014)

9. M.I. Solihin, Wahyudi, M.A.S. Kamal, A. Legowo, Objective function selection of GA-based PID control optimization for automatic gantry crane, Int. Conf. Comput. Commun. Eng., 883-887 (2008)

10. Y.N. Petrenko, S.E. Alavi, Fuzzy logic and genetic algorithm technique for non-linear system of overhead crane, IEEE Reg. 8 Int. Conf. Comput. Technol. Electr. Electron. Eng., 848-851 (2010)

11. C. Pedret, R. Vilanova, R. Moreno, I. Serra, A refinement procedure for PID controllers, Electr. Eng., 88, 3, 215-221 (2006)

12. K.K. Tan, S. Huang, R. Ferdous, Robust self-tuning PID controller for nonlinear systems, J. Process Control, 12, 7, 753-761 (2002)

13. D. Valério, J.S. Da Costa, Tuning-rules for fractional PID controllers, IFAC Proc. Vol., 2, 1, 28-33 (2006)

14. Z.-L. Gaing, A particle swarm optimization approach for optimum design of PID controller in AVR system, IEEE Trans. Energy Convers., 19, 2, $384-$ 391 (2004)

15. W.-D. Chang, J.-J. Yan, Adaptive robust PID controller design based on a sliding mode for uncertain chaotic systems, Chaos, Solitons and Fractals, 26, 1, 167-175 (2005)

16. W. Xiuli, W. Yongji, Z. Hui, H. Xiaoyong, PSOPID: A Novel controller for AQM routers, IFIP Int. Conf. Wirel. Opt. Commun. Networks, 1-5 (2006)

17. W.A.W. Azhar, M. Nafrizuan, S. Azlyna, Tuning of optimum PID Controller parameter using particle swarm optimization algorithm approach, National Conf. Software Eng. Comput. Syst, 1-7 (2007)

18. R. Poli, J. Kennedy, T. Blackwell, Particle swarm optimization, Swarm Intell., 1, 1, 33-57 (2007)

19. Y. Shi, R.C. Eberhart, A modified particle swarm optimizer, 1998 IEEE Int. Conf. Evol. Comput. Proc. IEEE World Congr. Comput. Intell. (Cat. No.98TH8360), 69-73 (1998)

20. Q. Bai, Analysis of particle swarm optimization algorithm, Comput. Inf. Sci., 3, 1, 180-184 (2010)

21. Y. Shi, R.C. Eberhart, Particle swarm optimization: developments, applications and resources, Proc. 2001 Congr. Evol. Comput. (IEEE Cat. No.01TH8546), 1, 81-86 (2001)

22. R.C. Eberhart, J. Kennedy, A new optimizer using particle swarm theory, MHS'95. Proc. Sixth Int. Symp. Micro Machine Human Sci., 39-43 (1995)

23. M.I. Solihin, Wahyudi, M.A.S. Kamal, A. Legowo, Optimal PID controller tuning of automatic gantry crane using PSO algorithm, 2008 5th Int. Symp. Mechatronics its Appl., 25-29 (2008) 